\title{
"EU QUERO VOTAR PARA PRESIDENTE": UMA ANÁLISE SOBRE A CAMPANHA DAS DIRETAS
}

Edison Ricardo Emiliano Bertoncelo

\section{Introdução}

O tema central deste artigo é a investigação da dinâmica e significado da Campanha das Diretas-Já. Nela, vários grupos sociais e políticos se uniram e organizaram manifestações públicas diversas (comícios, passeatas, caravanas etc.) para reivindicar o direito de escolher o Presidente da República pelo voto direto.

Mais do que uma campanha, na verdade trata-se de um movimento social (ver Sandoval, 1998). Movimentos sociais podem ser definidos como:

"coletividades agindo com algum grau de organização

e continuidade fora dos canais institucionais ou

organizacionais com o objetivo de desafiar ou defender

a autoridade existente, definida institucional ou

culturalmente, em um grupo, organização, sociedade... ou

ordem mundial do qual elas fazem parte" (Snow et al., 2004, p. 11 - tradução própria) ${ }^{1}$.

\footnotetext{
${ }^{1}$ Considerar movimentos como coletividades impede que eles sejam reificados como entidades monolíticas. Um movimento social é constituído por um conjun-
} 
Concebê-la dessa maneira permite iluminar aspectos que seriam marginalizados caso a tomássemos apenas como uma manobra das oposições partidárias ou como eventos de protesto isolados: vínculos de solidariedade, simbolização, crenças compartilhadas, desafios a autoridades políticas e códigos culturais, redes sociais sustentando ações coletivas, dimensões essas enfatizadas em várias definições de movimento social (entre outros, Dellaporta e Diani, 1999).

\section{A emergência da Campanha das Diretas-Já}

A campanha das diretas emergiu sob um regime militar-autoritário em uma conjuntura de grave crise política. É essencial investigar os processos autonomamente determinados (Skocpol, 1979) que geraram essa conjuntura e o modo pelo qual ela conformou a emergência dos protestos por eleições diretas.

A relação entre crise e movimentos sociais foi inicialmente investigada pela(s) teoria(s) do comportamento coletivo. 170 Nelas, os movimentos sociais são vistos como fenômenos de comportamento coletivo que emergem em períodos de ruptura dos mecanismos de controle social e dos imperativos morais, resultando em formas irracionais e desviantes de comportamento. Os períodos de crise são vistos como estados patológicos em que emergem comportamentos irracionais (para uma visão geral, ver Buechler, 2004). Diferentemente, para Michel Dobry (1986), o que diferencia conjunturas críticas de conjunturas rotineiras é o grau em que as ações dos atores sociais se orientam para as lógicas específicas que

to de atores, ligados através de redes sociais diversas, em relações de conflito e cooperação entre si. Por isso, a unidade de um movimento social é apenas fluida e relativamente precária (Melucci, 1995). Em segundo lugar, os movimentos sociais são caracterizados pelo uso de formas não convencionais de ação, por um lado, porque carecem de acesso rotineiro aos canais político-institucionais convencionais e, por outro, porque formas de mobilização não convencionais são mais eficazes para dramatizar as concepções alternativas que os movem. Por fim, os movimentos sociais são atores centrais nos processos de confrontação política, em que códigos culturais e autoridades políticas são desafiados (Tarrow e Tilly, 2007). 
regulam os setores que compõem o sistema social, e não propriamente a elevação de tendências de desequilíbrios ou a escalada de conflitos sociais e políticos. Em conjunturas críticas, há um processo de dessetorialização conjuntural do sistema social. As lógicas setoriais perdem eficácia na regulação das orientações de ação e se tornam referências pouco precisas para os cálculos dos atores, o que implica uma redução da autonomia dos setores e de sua capacidade em delimitar as arenas de conflito e em definir o valor relativo dos recursos. Como consequência, forma-se um espaço ampliado de interação, em que se confrontam jogadas intersetoriais que opõem atores, recursos e linhas de ação de setores distintos.

A perspectiva de Dobry permite estabelecer uma relação bidirecional entre conjunturas críticas e protestos coletivos, que são um tipo de mobilização intersetorial (ou multissetorial). $\mathrm{O}$ aumento relativo daqueles tende a aumentar a fluidez do sistema social. Isto, por sua vez, tende a gerar um contexto ampliado de interações em que jogadas intersetoriais se multiplicam. Com base nisso, pode-se argumentar que a campanha das diretas foi, em parte, o produto da multiplicação de jogadas intersetoriais em um contexto ampliado de conflito, produzido por uma conjuntura de grave crise política que se materializou especialmente a partir de 1983.

Essa conjuntura de crise política teve três dimensões distintas. Em primeiro lugar, havia a dimensão da crise de Estado, gerada pela drástica redução da capacidade estatal em promover o desenvolvimento capitalista e em intermediar os interesses sociais em esfera corporativa. Isso provocou uma erosão da aliança sociopolítica que dava sustentação ao padrão de dominação política materializado no Estado varguista (Sallum, 2004). Em segundo lugar, havia uma crise do regime, gerada pelas alterações das relações de poder entre os principais centros de poder político (especialmente o enfraquecimento do Executivo Federal vis-à-vis os Executivos Estaduais e Congresso Nacional) e pela crescente dificuldade em canalizar a par- 
ticipação popular para os (esvaziados) canais eleitorais. Por fim, havia uma crise de governo, caracterizada pelo enfraquecimento da autoridade presidencial, pela paralisia decisória e pela fragmentação da base de sustentação político-partidária do governo federal no Congresso Nacional.

Embora deflagrada apenas no início da década de 1980, essa conjuntura crítica foi gestada ao longo da década anterior. Destaco primeiramente as consequências do transbordamento do processo de abertura política em relação aos termos do projeto de distensão, iniciado com a ascensão de uma nova coalizão militar ao centro do Estado, que resultou na escolha do General Ernesto Geisel para a Presidência da República em 1974. A despeito do enorme gradualismo e dos casuísmos que marcaram a implementação desse projeto, a dinâmica do processo produziu resultados que o afastaram das intenções da coalizão dirigente. As eleições de 1982, especialmente, envolveram uma distribuição real de poder entre os atores políticos

172 (instaurando uma diarquia no sistema político), na medida em que as oposições partidárias (no caso, PMDB e PDT) conquistaram dez governadorias, passando a controlar parte da máquina estatal (Lamounier, 1988). Os resultados para a Câmara dos Deputados, em seu conjunto, também foram desfavoráveis ao PDS e aos dirigentes do regime. Embora o PDS tenha obtido o maior número de cadeiras, 235 no total, os demais partidos obtiveram 244, retirando a maioria parlamentar do partido governista na Câmara Federal. Com a ampliação da competição político-partidária, os partidos de oposição, especialmente o PMDB, lograram expandir-se nacionalmente e enraizar-se entre as camadas médias e populares (Sallum, 1996).

Além disso, as tentativas de desarticulação da comunidade de segurança e a restauração de algumas liberdades políticas e civis (entre elas a liberalização parcial da imprensa, especialmente da imprensa escrita) contribuíram para reduzir os níveis de repressão política e para expandir o espaço público não controlado pelo Estado. 
Em parte como resultado desses processos, a dinâmica sociopolítica de uma sociedade que se urbanizava e se industrializava (Faria, 1983) materializou-se mais fortemente na cena pública a partir do final dos anos de $1970^{2}$.

Excetuando-se as ações de guerrilhas e "grupos revolucionários", setores da Igreja Católica constituíram a única força de oposição societária ao regime militar até meados da década de 1970. No final dessa década, os protestos contra a ordem política autoritária se intensificaram, com as mobilizações de entidades profissionais e de associações estudantis e com a volta do movimento grevista à cena pública (Noronha, 1991). Essa onda de protestos estimulou um "surto associativista", uma redefinição das formas de ação coletiva e a formação de novas identidades coletivas, tanto entre frações de trabalhadores manuais quanto entre profissionais de camadas médias, em torno de reivindicações por diversos direitos civis, políticos e sociais (Cardoso, 1983; Boschi, 1987; Rodrigues, 1991). Fundamentalmente, houve um processo de autonomização política de amplas camadas sociais, que extravasou o aparato corporativo-estatal, sustentando a construção de formas mais pluralistas de articulação de interesses e demandas (Diniz, 1991).

Em 1983, esses fenômenos se conjugaram a uma profunda crise econômica, que já se delineava desde o final da década anterior. Sob o impacto de choques externos (aumento do preço do petróleo e das taxas de juros internacionais), somados ao enorme endividamento externo da economia brasileira e aos efeitos da moratória mexicana de 1982, a capa-

\footnotetext{
${ }^{2}$ A importância das transformações socioestruturais - que alteraram profundamente a feição da sociedade brasileira em cerca de 30 anos (1950-1980) - para a emergência da campanha das diretas não pode ser subestimada. Como tento mostrar em outro trabalho (Bertoncelo, 2007, pp. 54-59), os processos de urbanização e industrialização e as alterações na estrutura ocupacional geraram condições para a renovação dos padrões associativos e de articulação de interesses, além de terem criado novos campos de conflito social, especialmente em torno da autonomização política de amplas camadas sociais.
} 
cidade do Estado em se manter como polo organizador da economia nacional praticamente esgotou-se (Sallum, 2004).

A estratégia de combate à crise, que privilegiava medidas de impacto recessivo, gerou enormes reações internas, o que enfraqueceu as bases de apoio social e político das autoridades governamentais. De um lado, camadas empresariais dos setores público e privado, membros da aliança sociopolítica articulada no Estado, opuseram-se fortemente à estratégia recessiva porque viam no "crescimento econômico o valor básico a ser alcançado" pelos dirigentes estatais (Sallum, 2004, p. 50). Além disso, temiam que as consequências políticas e sociais das medidas recessivas pudessem colocar em risco o processo de abertura política (Bertoncelo, 2007). De outro lado, profissionais assalariados do setor privado, funcionários públicos e frações de trabalhadores manuais se mobilizaram em ações de protesto visando especialmente à política de redução da massa salarial. Entre outras coisas, isso resultou em um aumento do 174 número de greves (393 em 1983 contra 144 no ano anterior) e na realização, em julho desse ano, da primeira greve geral durante o regime militar, que mobilizou especialmente trabalhadores manuais das indústrias modernas (Sandoval, 1994).

Além de materializar o enorme descontentamento de amplas camadas sociais em relação à situação econômica e política, a intensificação dos protestos sociais funcionou como um mecanismo de pressão sobre os políticos profissionais em todos os partidos, que se tornavam mais sensíveis diante das pressões da opinião pública, e mais autônomos diante das orientações do núcleo do regime no contexto da abertura política (Kugelmas e Sallum, 1993). Como consequência disso, produziram-se alterações no funcionamento do sistema político, modificando a relação entre os centros de poder nos âmbitos nacional e estadual e desagregando a base de apoio político-partidária do regime militar (Bertoncelo, 2007).

Os processos analisados anteriormente (rachaduras na base de sustentação do Estado, erosão do apoio sociopolí- 
tico ao regime militar, crescimento político-institucional e organizacional das oposições partidárias e a crescente autonomização política de camadas sociais) alteraram a estrutura de oportunidades políticas confrontando os vários atores sociais e políticos ${ }^{3}$. Essa conjuntura facilitou ações contenciosas das oposições visando ao esvaziamento da ordem política autoritária (e também de dissidências dentro do regime), pois reduziu a eficácia dos recursos à disposição dos dirigentes do regime para o controle dos processos políticos e sociais. Isso se materializou especialmente nas tentativas fracassadas do presidente Figueiredo em unir as diversas correntes no PDS e no regime em torno de uma candidatura presidencial única, leal aos ideais da "Revolução de 1964", fazendo valer a maioria dos votos desse partido no Colégio Eleitoral (segundo as regras institucionalmente estabelecidas, a escolha do sucessor de Figueiredo seria feita por delegados do Colégio Eleitoral em janeiro de 1985).

Essa crescente dificuldade de coordenação do processo sucessório foi interpretada por setores majoritários das oposições partidárias ${ }^{4}$ (especialmente o PMDB) como uma oportunidade para superar os limites institucionais impostos à sucessão presidencial e conquistar a Presidência já em 1985. Havia, de um lado, uma corrente liderada pelo deputado federal Ulysses Guimarães - minoritária dentro do PMDB

\footnotetext{
${ }^{3} \mathrm{O}$ conceito de estrutura de oportunidades políticas foi usado para captar as mudanças em dimensões do sistema político que alteram as oportunidades/ameaças de ação coletiva por parte de desafiadores ao afetarem as chances percebidas de sucesso e repressão (Tarrow, 1998; Tilly e Tarrow, 2007). Desafiadores são atores coletivos que não possuem acesso rotineiro aos atores e recursos governamentais. Em geral, as dimensões dinâmicas e informais do sistema político (o surgimento de divisões entre as elites, mudanças nos alinhamentos políticos) são enfocadas para explicar o timing dos ciclos de protesto (McAdam, 1996). Diferentemente, as dimensões mais estáveis e formais do sistema político (grau de centralização do poder político, estrutura partidária) são usadas para explicar as escolhas diferenciais de estratégias de mobilização e de repertórios de ação coletiva (ver Rucht, 1996; Kriesi et al., 1998).

${ }^{4}$ Esse termo é uma simplificação que omite os conflitos entre os partidos políticos (PMDB, PDT, PT e PTB) que não faziam parte da base de apoio político-partidário do regime, e que não poderão ser analisados nos limites deste artigo.
} 
- que reivindicava o restabelecimento da eleição direta para a escolha do sucessor de Figueiredo. Embora essa proposta tenha sido inicialmente colocada em fins de 1982, ela se fortaleceu com a apresentação da emenda Dante de Oliveira, em março de $1983^{5}$. Uma campanha popular por eleições diretas foi vista como um elemento de pressão para angariar votos pedessistas ou simplesmente para forçar o núcleo do regime a negociar em termos melhores para as oposições ${ }^{6}$. Por outro lado, uma facção liderada pelo governador de Minas Gerais, Tancredo Neves, majoritária dentro do partido e com apoio da maioria dos governadores, calculava que as divisões dentro do PDS se intensificariam com o crescimento da candidatura de Paulo Maluf, o que abriria espaço para uma "conciliação" entre facções pedessistas e oposicionistas para o apoio de um "candidato de consenso" (no qual Tancredo esforçava-se por se enquadrar) no Colégio Eleitoral.

Talvez tenha sido essa divisão dentro do maior partido 176 de oposição o principal fator explicativo do fracasso inicial de setores do PMDB, em relação ao PT e a alguns grupos sociais, em deflagrar uma campanha por eleições diretas em 1983 (Bertoncelo, 2007, pp. 99-111). Essa configuração de forças foi alterada no final desse ano. A evidência de que havia um enorme potencial de mobilização em torno da reivindicação por eleições diretas (como indicavam pesquisas de opinião pública e mobilizações de grupos sociais na cena pública), somada à incerteza que marcava os rumos da sucessão presidencial (incerteza aumentada pela abdicação de Figueiredo da coordenação do processo sucessório, em

\footnotetext{
${ }^{5}$ Caso aprovada, a emenda restituiria a eleição direta para a sucessão de Figueiredo em novembro de 1984.

${ }^{6}$ Eram necessários 2/3 dos votos nas duas casas legislativas para aprovar mudanças constitucionais, isto é, 320 votos na Câmara e 46 votos no Senado. Os parlamentares dos partidos de oposição somavam 244 na Câmara e 24 no Senado. Neste, as dificuldades eram ainda maiores devido aos assim denominados senadores "biônicos", por terem sido escolhidos pelos dirigentes do regime por meio das assembleias estaduais, sendo previsivelmente mais leais ao governo federal.
} 
dezembro de 1983), alteraram as estratégias da "ala moderada” das oposições partidárias, especialmente dos governadores. Calculando que uma ampla mobilização societária poderia aumentar os recursos das oposições na conformação do processo político, eles decidiram adotar um discurso mais enfático de defesa de eleições presidenciais diretas na cena pública e, mais fundamentalmente, decidiram apoiar as mobilizações por eleições diretas.

Em suma, processos autonomamente determinados ocorrendo em contextos de ação diversos interpenetraramse, constituindo uma conjuntura de crise política em que se multiplicaram as jogadas intersetoriais visando às disputas em torno da sucessão presidencial. A campanha das diretas foi, ela própria, produto dos esforços de construção de uma unidade entre diversas jogadas intersetoriais partindo de atores sociais e políticos que, orientando-se por ideais democráticos, buscavam liquidar o regime militar superando os limites impostos à sucessão presidencial.

\section{A construção simbólica da campanha das diretas}

Tarrow (1998) sublinha que a ação coletiva exige a coordenação de atores coletivos e individuais, relativamente isolados e dispersos, em ação concertada. Os esforços por mobilizar recursos e atores de forma coordenada são, em grande medida, levados a cabo pelas chamadas estruturas de mobilização, que incluem desde organizações formalmente ligadas a um movimento social até aquelas que são apropriadas (Igreja, sindicatos, vizinhança, associações profissionais, instituições políticas etc.) no processo de mobilização (McCarthy, 1996; McAdam et al., 2001; Stagenborg, 2002).

Com base nisso, pode-se dizer que alguns governadores (ou melhor, governadorias) oposicionistas tiveram um papel decisivo para a deflagração da campanha das diretas. Além de controlarem recursos importantes (como o controle sobre as polícias militares, essencial para garantir a segu- 
rança dos participantes), eles foram atores centrais (pelo menos inicialmente) na coordenação do processo de mobilização de recursos, um fator necessário para transformar as oportunidades percebidas de superação da ordem política autoritária em ações de protesto ${ }^{7}$.

A realização relativamente bem-sucedida de um conjunto de manifestações por eleições diretas no início de 1984 (tanto em capitais quanto em municípios interioranos, levando às ruas mais de 400 mil pessoas em janeiro e cerca de 700 mil no mês seguinte) incentivou outros grupos sociais e políticos a mobilizar-se. Em parte, isso resultou na multiplicação dos comitês pró-diretas em âmbito nacional, processo que se alimentou da maior organização dos partidos de oposição e da maior autonomia política e capacidade organizacional de diversos grupos sociais. De fato, os comitês, que reuniam os partidos de oposição, membros do grupo pró-diretas do PDS, além de associações e entidades sociais diversas, cons178 tituíram-se em grande medida apropriando-se do aparato organizacional existente e transformando-o em estruturas de mobilização. Esse foi um dos fatores que permitiu expandir a luta por eleições diretas pelo território nacional ${ }^{8}$.

\footnotetext{
${ }^{7}$ Para a realização do comício da Praça da Sé (ocorrido na cidade de São Paulo em 25 de janeiro de 1984), o governador Franco Montoro (com o apoio do prefeito por ele indicado, Mario Covas) garantiu transporte gratuito ao local da manifestação, liberando as catracas do metrô, ônibus e trens. O secretário de segurança, Miguel Reale Jr., reuniu-se com o ministro da Justiça, Ibrahim Abi-Ackel, para assegurar-lhe que a segurança do evento seria feita pela polícia militar (havia o temor de que as tropas do Exército pudessem ser mobilizas pelo regime militar, o que, de fato, não ocorreu, embora as tropas estivessem em estado de prontidão). Por sua vez, os secretários do interior e de negócios metropolitanos, respectivamente Chopin Tavares de Lima e Almino Afonso, estimularam os prefeitos da Grande São Paulo a organizar caravanas para o local da manifestação. Em parte como resultado desses esforços, o comparecimento de cerca de 300 mil pessoas superou em muito as expectativas iniciais dos organizadores. Esforços semelhantes foram fundamentais para a realização de várias outras manifestações pró-diretas (ver Bertoncelo, 2007, pp. 120-137, 146-149, 161-167).

${ }^{8}$ A Caravana das Diretas, organizada por Ulysses Guimarães, Lula e Doutel de Andrade (presidentes nacionais do PMDB, PT e PDT, respectivamente), percorreu várias cidades das regiões Norte e Nordeste nos meses de janeiro e fevereiro.
} 
Os processos de transformação de oportunidades diversas em recursos e de criação e apropriação de estruturas de mobilização são mediados por processos interpretativos que ocorrem no interior da ação coletiva (McAdam et al., 1996).

Os estudos sobre os chamados quadros interpretativos de ação coletiva salientam a importância do sentido [meaning] em mediar a relação entre organização, oportunidades e mobilização. Os movimentos sociais são vistos como atores engajados em um trabalho de significação ou de construção de sentidos, do qual resultam os quadros interpretativos. Como "conjuntos de crenças e sentidos orientados para a ação", eles geram interpretações da realidade social e de seus objetos a fim de mobilizar potenciais participantes, obter o apoio de espectadores e desmobilizar adversários, buscando, assim, "inspirar e legitimar as atividades e campanhas de uma organização de movimento social" (Snow e Benford, 2000, p. 614 - tradução própria; Snow et al., 1986; Snow e Benford, 1988; Snow, 2004).

Nesta perspectiva, a cultura tende a ser vista como um repertório de símbolos, narrativas, definições que são apropriadas pelos atores nos processos de mobilização coletiva (Zald, 1996). Embora tal concepção avance em relação a outras que tomam a cultura como um mero epifenômeno ou que simplesmente ignoram os componentes culturais da ação coletiva (como o mainstream da teoria da mobilização de recursos), ela tende a retratá-la como um conjunto de elementos que existem concretamente fora dos atores, para os quais eles se orientam estrategicamente. Como consequência disso, temos que a lógica que informa a simbolização dos movimentos sociais parece responder fundamentalmente às exigências do ambiente externo que os confronta, quer dizer, a necessidade de legitimação de interesses e ações para públicos mais amplos (para uma crítica semelhante, ver Steinberg, 2002) ${ }^{9}$.

\footnotetext{
${ }^{9}$ Nas palavras de dois dos autores mais importantes na área: "os processos estratégicos associados às práticas interpretativas de movimentos sociais têm recebido muito mais atenção empírica [do que os processos discursivos]. Por processos estratégicos,
} 
Essa concepção instrumental pode ser superada se tomarmos a cultura não apenas como um repertório, mas como um contexto não contingente que estrutura a ação segundo uma lógica específica (Alexander, 1989). O contexto cultural é constituído por padrões simbólicos que "constrangem e possibilitam a ação ao estruturarem os compromissos normativos dos atores e seu entendimento do mundo e suas possibilidades dentro dele" (Emirbayer, 1996, p. 110). Nesse sentido, a cultura, ou melhor, uma estrutura cultural (Rambo e Chan, 1990) é um componente constitutivo da ordem social, informando a "estrutura das instituições sociais, a natureza da cooperação e conflito sociais, e as atitudes e predisposições da população" (Sewell, 1985, p. 61 - tradução própria).

Então, os quadros interpretativos de ação coletiva podem ser vistos como o produto da interação entre padrões simbólicos e a estrutura de oportunidades que confrontam os atores externamente, ou seja, como o pro180 duto da formulação de uma estrutura cultural em contextos socioestruturais específicos (formados por redes interpessoais e interorganizacionais) ${ }^{10}$. Nesse sentido, eles canalizam os esforços dos atores para aquilo que é possível e desejável alcançar dadas as condições existentes. Obviamente, o que

referimo-nos às práticas interpretativas que são deliberadas, utilitárias, orientadas para objetivos: quadros interpretativos são construídos e empregados para alcançar um objetivo específico - recrutar novos membros, mobilizar adeptos, adquirir recursos e assim por diante." (Snow e Benford, 2000, p. 624 - tradução própria). Mesmo em enfoques teóricos que empregam uma concepção de cultura diversa, essa mesma lógica aparece. Swidler (1995), que utiliza uma concepção de cultura inspirada em Geertz (1973), argumenta que "diferentes tipos de regime e diferentes formas de repressão geram diferentes tipos de movimentos sociais com diferentes táticas e diferentes tipos de cultura interna", ou seja, "os movimentos sociais desenvolvem suas culturas para se ajustarem às instituições existentes [...]” (p. 37 - tradução própria).

${ }^{10}$ Seguindo Kane (1991), podemos distinguir entre autonomia analítica e concreta da cultura. Analiticamente, a cultura pode ser "separada" de outras estruturas, sendo concebida como um sistema simbólico que gera padrões classificatórios operando em termos de oposições binárias. Concretamente, a cultura é formulada por atores sociais como um sistema de crenças ou valores, e de práticas rituais. Neste nível, encontra-se o processo de mútua constituição entre estrutura cultural e estrutura social. 
é possível alcançar e os meios para isso não são dados aos atores. Daí, as disputas (nos processos discursivos) que ocorrem em torno da construção de quadros interpretativos.

Não será possível reconstruir aqui em detalhes as disputas que conformaram o quadro interpretativo que emergiu no contexto das mobilizações por eleições diretas ${ }^{11}$. No entanto, podemos dizer que seus componentes principais foram assim construídos:

\section{Quadro 1}

Componentes do quadro interpretativo das Diretas-Já

\begin{tabular}{|c|l|}
\hline Diagnóstico & $\begin{array}{l}\text { O centro político da sociedade é visto como o principal respon- } \\
\text { sável pela grave situação socioeconômica e por suas consequên- } \\
\text { cias sociais e políticas (aumento do desemprego, redução da } \\
\text { renda, dentre outras). A enorme centralização do poder político } \\
\text { faz com que os custos do ajuste recaiam desigualmente sobre } \\
\text { as camadas sociais; }\end{array}$ \\
\hline Prognóstico & $\begin{array}{l}\text { O restabelecimento da eleição direta para a Presidência da Repú- } \\
\text { blica pode abrir maior espaço para a participação societária na } \\
\text { arena política e, com isso, permitir que as principais demandas } \\
\text { sociais sejam atendidas. O futuro governo, tendo como base um } \\
\text { presidente eleito diretamente pela população, teria maior repre- } \\
\text { sentatividade para implementar políticas de resolução dos princi- } \\
\text { pais problemas percebidos na sociedade; }\end{array}$ \\
\hline Motivação para agir & $\begin{array}{l}\text { A participação na campanha das diretas é uma forma de manifes- } \\
\text { tar a insatisfação diante da situação política, econômica e social } \\
\text { do país. O amplo apoio da população e dos partidos à luta por } \\
\text { diretas-já pode forçar os congressistas a aprovar a emenda Dante } \\
\text { de Oliveira, viabilizando a demanda pelo restabelecimento ime- } \\
\text { diato da eleição direta para presidente. }\end{array}$ \\
\hline
\end{tabular}

A construção desse quadro interpretativo apropriou-se de (e foi estruturada por) padrões simbólicos construídos ou reinterpretados no contexto da autonomização política de amplas camadas sociais, como a concepção ampla de democracia que informava as reivindicações diversas na cena públi-

\footnotetext{
${ }^{11}$ A reconstrução desse quadro interpretativo foi feita com base nos inúmeros manifestos, declarações e outros materiais produzidos pelos participantes da campanha das diretas (para exemplos, ver Bertoncelo, 2007, pp. 120-129).
} 
ca desde meados da década de 1970. Sublinhe-se que, ao associar a eleição direta para presidente à possibilidade de encaminhamento de diversas reivindicações e de superação da crise econômica de forma socialmente mais "justa”, esse modo de interpretar a luta pró-diretas criou condições propícias à formação de uma ampla coalizão sociopolítica de oposição ao regime militar e para sua ação unificada na cena pública.

Se, por um lado, o quadro interpretativo das diretas motivou atores sociais e políticos diversos a mobilizar recursos e apropriar-se de estruturas de mobilização, por outro, foi a mobilização dessa base organizacional (com o apoio de setores da imprensa escrita) que facilitou que a produção simbólica do movimento pelas diretas fosse difundida nacionalmente, a despeito do bloqueio imposto pelo regime militar ao principal meio de comunicação na época (a televisão).

\section{A reação do regime e a proposta de negociação}

182 Em uma onda de protestos, como argumenta Tarrow (1998), os movimentos sociais não apenas se aproveitam de oportunidades de mobilização, mas também as ampliam, tanto para si mesmos como para outros movimentos ou insurgentes. Além disso, os desafios produzidos por insurgentes geram contramobilizações por parte dos atores afetados por eles, que impactam igualmente sobre a estrutura de oportunidade do protesto coletivo. De um lado, vimos que os grandes comícios do início de 1984, especialmente o comício da Praça da Sé, demonstraram as oportunidades de ação a outros atores individuais e coletivos, incentivando-os a mobilizar-se em ação coletiva, o que expandiu a campanha por eleições diretas. De outro, temos o núcleo do regime e suas lideranças político-partidárias mobilizando-se para conter os efeitos da campanha sobre o processo político.

A campanha das diretas funcionou como um mecanismo de materialização da vontade majoritária por eleições diretas existente na sociedade. Isso constituiu um elemento de pres- 
são sobre os políticos profissionais do PDS, cujo destino político dependia cada vez mais da aproximação com o eleitorado. Muitos entre eles calculavam que a postura oficial da cúpula pedessista - definida em reunião em janeiro de 1984, de defender a legitimidade do Colégio Eleitoral - poderia produzir um enorme desgaste político-eleitoral ao partido, possivelmente ameaçando seu desempenho nas eleições de 1986. Por isso, a multiplicação e ampliação das mobilizações por eleições diretas acabaram por fragmentar ainda mais esse partido ${ }^{12}$.

Inicialmente, a estratégia do núcleo do regime para conter os efeitos da campanha das diretas baseou-se em tentativas de reconstruir a unidade do PDS em torno de uma única candidatura apoiada pelas várias facções. Esses esforços não tiveram os efeitos desejados. De fato, com a crescente polarização entre as candidaturas de Paulo Maluf e Mario Andreazza, era improvável que surgisse um "nome de consenso" no partido (Bertoncelo, 2007, p. 144).

Diante disso, o núcleo do regime modificou sua estratégia, balizando-a em termos de dois elementos. Em pronunciamento nacional em 31 de março de 1984, Figueiredo manifestou a intenção de enviar uma emenda que, entre outras coisas, restabeleceria a eleição direta para a sucessão de seu sucessor. Denomino esse elemento de "proposta da negociação", porque, em certo sentido, buscava atenuar o desgaste político do PDS e do governo ao atender parcialmente às demandas das oposições. A isso, somava-se um outro elemento: o da pressão militar. No mesmo pronunciamento, Figueiredo afirmou que a eleição de seu sucessor se daria sob as regras já estabelecidas e defendeu a legitimidade do Colégio Eleitoral. Isso expressava a disposição dos setores militares do regime, apoiados pelas facções mais

\footnotetext{
${ }^{12}$ Surgiu um grupo pró-diretas, cuja lista de adesões, segundo suas lideranças, atingiu cerca de 60 deputados federais em março de 1984. Além disso, alguns políticos pedessistas subiram aos palanques das diretas, não apenas vereadores e prefeitos, mas também deputados estaduais e federais (Bertoncelo, 2007, p. 130).
} 
conservadoras do PDS, em vetar uma possível aprovação da emenda Dante.

Embora a unidade do front oposicionista sempre tenha sido muito tênue, a "proposta de negociação" (somada à percepção da insatisfação de setores militares com a campanha) foi interpretada por algumas lideranças oposicionistas (especialmente aquelas gravitando em torno de Tancredo Neves) como uma oportunidade para "relançar" a "estratégia da conciliação" no jogo sucessório, adotando uma postura mais moderada na cena política. Não tanto pela emenda alternativa a ser apresentada pelo Executivo Federal, que não trazia datas e não negociava o essencial. O ponto é que a manutenção do ritmo crescente das mobilizações pró-diretas poderia ser interpretada, no campo adversário, como uma recusa a negociar, radicalizando ainda mais as disputas políticas e, no limite, ameaçando as conquistas obtidas pelas oposições ao longo do processo de abertura política. Por isso, apesar da postura ofi184 cial do PMDB (e dos demais partidos de oposição) em sustentar a luta pelo restabelecimento imediato das eleições diretas, surgiram evidências de tentativas de frear a campanha pródiretas por parte de lideranças oposicionistas (especialmente os governadores) (Bertoncelo, 2007, pp. 153-157).

Essas tentativas, no entanto, não foram bem-sucedidas. Na verdade, ao longo do tempo, o crescimento da base organizacional da campanha contribuiu para reduzir o controle do PMDB e dos governadores sobre ela. Além disso, como vimos, a construção simbólica da campanha como um movimento que buscava superar o regime militar-autoritário e instaurar uma sociedade democrática mais aberta à participação popular permitiu que a luta pelo voto direto penetrasse profundamente na sociedade (como nos revelam as festas carnavalescas que fizeram da eleição presidencial seu principal tema, as iniciativas das duas maiores torcidas de futebol do país, Corinthians e Flamengo, em constituir alas pró-diretas, levando faixas e bandeiras das diretas aos estádios). Embora 
setores das oposições partidárias, aparentemente prevendo a derrota da emenda Dante de Oliveira, já se preparassem para "negociar" uma candidatura no Colégio Eleitoral, as mobilizações societárias que alimentavam a campanha por eleições diretas cresciam continuamente (Bertoncelo, 2007, p. 158).

Apoiada nessa larga base de apoio societário, a campanha produziu as maiores manifestações pelas diretas (e também da história brasileira) em abril. Os comitês pró-diretas tiveram um papel central na coordenação dos eventos, especialmente devido à resistência de governadores oposicionistas em participar mais ativamente da organização deles (idem, p. 168). A expectativa de bom comparecimento aos eventos pressionou os governadores de volta aos palanques. Os eventos de maior destaque foram, sem dúvida, os comícios da Candelária, no Rio de Janeiro, e do Vale do Anhangabaú, em São Paulo.

Além de ter levado mais de um milhão de pessoas às ruas, o comício da Candelária (realizado em 10 de abril) logrou romper a censura estabelecida pelo regime sobre as emissoras de televisão. A Rede Globo, que até então havia omitido a luta pelas diretas de seus noticiários, abriu amplo espaço para a manifestação do Rio em sua programação (Bertoncelo, 2007, pp. 163-164). Em 16 de abril, assistiu-se à maior manifestação da campanha, a passeata-comício no Vale do Anhangabaú, que reuniu cerca de 1,5 milhão de pessoas. Novamente, o bloqueio à censura foi quebrado, e trechos da passeata e dos discursos foram transmitidos ao vivo.

A mudança de posicionamento do principal órgão da imprensa nacional quanto à campanha das diretas foi em parte uma jogada tática, de afastamento, embora ainda cauteloso, em relação ao regime militar, o que acabou por isolá-lo ainda mais. Para além desse impacto político, a ruptura ao bloqueio à imprensa televisiva permitiu que a ritualização da campanha se estendesse mais fortemente pela sociedade. Ou seja, através da TV na reta final da campanha, milhões de brasileiros puderam participar emocionalmente na luta por eleições diretas. 
As grandes manifestações do mês de abril levaram mais de três milhões de pessoas às ruas em várias regiões do país (houve comícios em várias capitais, como em Recife, Natal, Goiânia, Porto Alegre, Vitória, Salvador). O impacto por elas produzido talvez pudesse ter gerado recursos suficientes para que as forças oposicionistas e dissidências do PDS obtivessem os números necessários para aprovar a emenda Dante na Câmara dos Deputados, não fosse a mobilização do núcleo do regime. A estratégia de conter os efeitos da campanha das diretas, combinando elementos de negociação e de intervenção militar, foi implementada oficialmente. De um lado, o governo acenou com a possibilidade de atender a algumas das demandas das oposições e de dissidências no PDS, embora postergasse a sua realização. Em 16 de abril, Figueiredo anunciou em cadeia nacional de rádio e TV o envio de uma emenda ao Congresso Nacional que restabelecia as eleições diretas para Presidente em 1988 186 e as eleições nas capitais em 15 de novembro de 1986; reduzia o mandato presidencial para quatro anos e aumentava prerrogativas legislativas, entre outras medidas. De outro, o governo tomava a iniciativa de sublinhar o veto militar ao restabelecimento imediato da eleição presidencial direta, com a declaração das Medidas de Emergência em Brasília e municípios próximos por 60 dias (em 18 de abril), impedindo o acesso de caravanas, a realização de manifestações nas localidades e a transmissão ao vivo da votação.

O resultado já é sabido: a emenda Dante foi rejeitada. O principal significado dessa derrota foi o afastamento das "massas" da escolha do futuro presidente e a restrição das disputas sucessórias à escolha indireta pelos delegados do Colégio Eleitoral. Com a manutenção das regras sucessórias, o núcleo do regime conseguiu controlar os efeitos mais transformadores da crise política desencadeada em 1983 e intensificada no início do ano seguinte (Sallum, 2004; Bertoncelo, 2007). 


\section{Vitória das Diretas-Já: efeitos políticos e significado simbólico}

Na literatura dos Novos Movimentos Sociais, as dimensões subjetiva e cultural são vistas como centrais aos movimentos sociais contemporâneos. Isso é entendido como um produto da transformação das sociedades industriais em pós-industriais (entre outros, Touraine, 1985; Melluci, 1985; Eder, 1985). No contexto dessas profundas mudanças macroestruturais - que transformaram o modo de produção e as formas de estratificação social - emerge um novo campo de conflitos sociais em torno da construção e preservação de espaços para a formação de identidades pessoais e para a reivindicação de demandas universalistas. Daí, a ênfase sobre o impacto dos movimentos sociais contemporâneos sobre os códigos culturais.

Diferentemente, as Teorias do Processo Político e da Mobilização de Recursos enfatizam os efeitos de movimentos sociais sobre as estruturas formais e alianças informais do sistema político, que podem resultar na ampliação do acesso ao processo de tomada de decisões políticas para desafiadores e/ou em transferências de poder entre os contendores (Giugni, 1998).

Seguindo estudos mais recentes, que tentaram sintetizar os argumentos acima (Diani e Dellaporta, 1999; Alvarez et al., 2000), busco sublinhar tanto os efeitos políticos quanto os significados culturais associados às ações do movimento pelas diretas.

Anteriormente, a campanha das diretas foi concebida como o produto de uma conjuntura de crise política. Gostaria agora de salientar que a campanha foi um processo que conformou a crise política autonomamente, ampliando seus contornos.

Embora não tenha logrado seu objetivo principal, o movimento pelas diretas enfraqueceu fortemente o regime militar e as bases de sustentação do Estado Varguista, reduzindo a capacidade dos dirigentes do regime e das lideran- 
ças pedessistas de conduzir o processo político em moldes favoráveis à reprodução de suas posições de poder.

Ressalte-se, em primeiro lugar, que o amplo apoio sociopolítico à campanha isolou o núcleo do regime, forçando-o a ceder, parcialmente é verdade, às pressões vindas das ruas, esvaziando-o de seu caráter autoritário. No plano políticopartidário, vimos como o grupo pró-diretas e os setores liberais no PDS, não-alinhados às candidaturas de Paulo Maluf e Mário Andreazza e que aceitavam "negociar” com as oposições, ganharam força na conjuntura política desencadeada pela campanha.

No plano societário, a campanha afastou irremediavelmente parcelas significativas das camadas empresariais das orientações dos dirigentes do regime no campo sucessório. Ressalte-se que, apesar do empenho das lideranças da campanha em atrair lideranças empresariais, estas não subiram aos palanques das diretas. De fato, boa parte delas preferia 188 uma sucessão conduzida dentro das regras institucionalmente estabelecidas, de modo que se evitassem os efeitos sociais potencialmente mais transformadores associados a uma eleição direta. Entretanto, tais lideranças não estavam tampouco alinhadas com as orientações do chefe do Executivo federal e dos dirigentes militares, temerosas de que um sucessor saído diretamente das hostes do regime não tivesse o apoio societário e político necessário para promover as medidas de ajuste econômico de modo eficiente. A enorme mobilização sociopolítica em torno da campanha reforçou essa percepção (Bertoncelo, 2007, pp. 191-193). Por isso, a escolha preferida recaía sobre o nome de Aureliano Chaves. Sua candidatura poderia ser potencialmente viabilizada dentro do PDS para a eleição indireta. Além disso, pelo fato de o vice-presidente ter se posicionado favoravelmente à principal demanda das oposições ao longo da campanha das diretas (embora não participasse dela diretamente), Aureliano tornou-se o postulante à Presidência menos impopular dentro do PDS. 
Em segundo lugar, o apoio maciço da população à campanha das diretas acelerou o processo de deslegitimação do regime, questionando o principal mecanismo de sua reprodução, o Colégio Eleitoral (Lamounier, 1985). Mais fundamentalmente, o movimento pelas diretas afetou as bases mais profundas do regime militar e o padrão de dominação política longamente estabelecido nos mecanismos do Estado Varguista. Neste ponto, sobressai-se o impacto do movimento das diretas sobre os padrões simbólicos que informavam as estruturas políticas.

Em sua análise sobre o caso Watergate, Alexander (1988) investiga os processos culturais (como ritualização e sacralização) em contextos de crise política. Estes são tomados, segundo Parsons, como momentos de generalização. Neles, o foco de atenção dos atores generaliza-se do nível dos objetivos, interesses e poder para o nível mais fundamental dos valores, que são padrões simbólicos generalizados que informam os códigos e as normas que regulam a autoridade política e os processos de resolução de interesses. Esses valores constituem o chamado "centro sagrado" da sociedade (Shils, 1975). Daí a forte ritualização dos processos sociais em tais períodos, em que os atores experimentam, de forma não mediada, valores fundamentais e reinterpretam ou reafirmam o sistema de classificação. Embora a análise de Alexander sobre o caso Watergate seja um tanto idealista por não incorporar sistematicamente o modo pelo qual o ambiente material da ação limita o processo de generalização e constrange os processos culturais, a ideia de que, em períodos de crise, há uma intensificação dos processos de ritualização em que os atores enfocam mais fortemente uma realidade transcendente pode ser bastante útil para a literatura de movimentos sociais.

De fato, toda ação coletiva possui um componente ritualístico, pois ela materializa crenças culturais compartilhadas pelos atores (crenças são fórmulas conceituais que articulam os significados dos símbolos - Kane, 1991). Em 
ondas de protesto e especialmente em situações revolucionárias, a ritualização expande-se pelo tecido social: atores frequentemente enfocam símbolos coletivos e invocam valores sociais. Em arenas sociais diversas, estruturas culturais dominantes podem ser contestadas e transformadas, dando origem a estruturas alternativas que fornecem categorias e princípios para a reinterpretação da realidade social e, por meio de suas obrigações morais, impulsionam os esforços dos atores no sentido de reconstruírem a ordem social e política. A energia emocional produzida nos rituais pode sedimentar vínculos de solidariedade e mobiliza conflitos (Collins, 1988; Tiryakian, 2005).

A crença fundamental que movia os atores do movimento pelas diretas era de que eleger diretamente o Presidente da República permitiria superar o regime militar-autoritário e fundar uma sociedade democrática, construída em torno de valores ou princípios, como igualdade (entendida de for190 ma muito ampla, como igualdade socioeconômica, igualdade racial, igualdade de gênero etc.), representatividade popular, liberdade política, entre outros. Emergindo dos discursos gerados nas redes que ligavam grupos sociais e políticos diversos (e que sustentaram o processo de autonomização política da sociedade), essa crença - que informou as estratégias dos atores nas tentativas de reconstrução da ordem política - materializou-se na ritualização ensejada pelo movimento.

Os eventos por eleições diretas povoaram ruas, praças, casas, entre outros, de símbolos coletivos fortemente carregados de carga moral e emocional. Ao entoarem o hino nacional ao final das manifestações, ao se vestirem com a indumentária das diretas, ao pintarem suas casas com as cores da campanha (o verde e o amarelo), ao trazerem heróis nacionais (como Tiradentes), artistas, cantores, jogadores de futebol às ruas e praças, os participantes reivindicavam representar a "nação" e seu "centro sagrado" (que ali buscavam reinterpretar e reconstruir). Por outro lado, o centro político da 
sociedade foi "profanizado", com a criação de bonecos satirizando figuras políticas importantes como "Paulo Maluco", "Mario Dazzar" e "Aureliano Chavão", a malhação de outros, representando Ministros de Estado, enterros simbólicos do regime militar, do Colégio Eleitoral, do presidente Figueiredo etc. Essa "profanização” do centro político em parte explica a ineficácia das tentativas do núcleo político do regime em colocar-se como "representante da sociedade". Nas palavras de alguém que viveu os acontecimentos, "a opinião pública não quer mais ouvir falar na continuação de nada que esteja ligado ao governo" (Veja, 25.4.1984, Carta ao Leitor).

A ritualização ensejada pelo movimento das diretas fez emergir "experiências liminares" (Alexander, 1988): os eventos das diretas foram, em alguma medida, fenômenos "fora do tempo e espaço" tradicionais, ensejando experiências separadas da vida institucional cotidiana ${ }^{13}$.

As oposições simbólicas construídas ou reinterpretadas nos processos de ritualização (de um lado, verde e amarelo = massas $=$ democracia $=$ sociedade melhor; de outro, preto $=$ elites políticas $=$ autoritarismo $=$ sociedade injusta $)$ impactaram fortemente sobre os padrões dominantes de classificação que informavam as estruturas políticas e relações sociais. Questionou-se o discurso incrustado na sociedade brasileira que associava as "massas" à desordem e à falta de autoridade e que fazia da tutela política sobre a sociedade um princípio básico dos regimes políticos (categorias essas que foram centrais às reivindicações de legitimidade do golpe militar de 1964). Por outro lado, erigiu-se a praça pública como lugar fundamental da luta política e da constituição autônoma de atores coletivos. Exigia-se ali um regime político efetivamente democrático, a

\footnotetext{
${ }^{13}$ Exemplifico isso com o comício da Candelária: o centro da cidade do Rio de Janeiro foi tomado por uma multidão, em uma terça-feira, em que o expediente de trabalho foi cancelado ou terminado antes do normal em boa parte das empresas. Além disso, a programação das emissoras de televisão foi alterada para permitir a cobertura do evento (Bertoncelo, 2007, pp. 162-164).
} 
redefinição dos contornos do espaço público e a construção de um Estado cuja legitimidade se assentasse em sua capacidade de aglutinar ampla representatividade sociopolítica.

Obviamente, muitas das promessas aí contidas não foram plenamente implementadas. Os processos de ritualização ensejados pelo movimento das diretas não penetraram a sociedade. Como vimos, havia grupos sociais e políticos que se opuseram às reivindicações trazidas pela campanha, em parte porque o restabelecimento imediato das eleições diretas para Presidente criaria condições pouco propícias para a realização de seus interesses. Ressalte-se, ainda, que a energia emocional canalizada pelos eventos da campanha foi em parte manipulada por grupos diversos para avançar interesses materiais e ideais específicos (o palanque das diretas era usado para criar ou reforçar vínculos de solidariedade com setores do eleitorado, a praça servia como um palco para demandas diversas, como a dos partidos comunistas que pediam sua legalização etc.). Apesar

192 disso, creio que a narrativa construída no movimento das diretas tenha informado, desde então, tentativas de reconstrução da vida institucional (afinal de contas, os regimes políticos e governos mais recentes ampliaram os canais para a participação mais efetiva da população no processo político), além de, provavelmente, ter alimentado outras manifestações de massa da sociedade brasileira, como as mobilizações em torno da Constituinte de 1988 e aquelas em torno do impeachment do presidente Fernando Collor.

\section{Edison Ricardo Emiliano Bertoncelo}

é doutorando em Sociologia na Universidade de São Paulo

\section{Referências bibliográficas}

ALEXANDER, J. 1988. "Culture and politics: 'Watergate' and Durkheimian sociology”. In: . Durkheimian sociology: cultural studies. Cambridge: Cambridge University Press. . 1989. "Action and its environments". In: et al. The micro-macro link. Berkeley: University of California Press. 
ALMEIDA, M.; SORJ, B. 1983. Sociedade e política no Brasil pós-64. São Paulo: Brasiliense.

ALVAREZ, S.; DAGNINO, E.; ESCOBAR, A. 2000. Cultura e política nos movimentos sociais latino-americanos. Belo Horizonte: Ed. UFMG.

BERTONCELO, E. 2007. A campanha das diretas e a democratização. São Paulo: Humanitas/Fapesp.

BOITO Jr., A. 1991 Sindicalismo brasileiro nos anos 80. Rio de Janeiro: Paz e Terra.

BOSCHI, R. 1987. A arte da associação. Rio de Janeiro: Iuperj.

BUECHLER, S. 2004. "The strange career of strain and breakdown theories of collective action". In: SNOW, D.; SOULE, S.; KRIESI, H. (orgs.). The blackwell companion to social movements. MA, Oxford, Australia: Blackwell Publishers.

CARDOSO, R. 1983. "Movimentos sociais urbanos: balanço crítico". In: ALMEIDA, M.; SORJ, B. Sociedade e política no Brasil pós-64. São Paulo: Brasiliense.

COLLINS, R. 1988. "The Durkheimian tradition in conflict sociology". In: ALEXANDER, J. (org.). Durkheimian sociology: cultural studies. Cambridge: Cambridge University Press.

DELLAPORTA, D.; DIANI, M. 1999. Social movements - An introduction. Londres: Backwell Publishers.

DINIZ, E. 1991. Crise, reforma do Estado e governabilidade. Rio de Janeiro: Fundação Getúlio Vargas.

DOBRY, M. 1986. Sociologia de las crisis politicas - La dinámica de las movilizaciones multisectoriales. Madrid: Siglo Veintiuno de España Editores.

EMIRBAYER, M. 1996. "Useful Durkheim". Sociological Theory, no 14(2), pp. 109-130.

FARIA, V. 1983. "Desenvolvimento, urbanização e mudanças na estrutura do emprego: a experiência brasileira dos últimos trinta anos”. In: ALMEIDA, M.; SORJ, B. Sociedade e política no Brasil pós-64. São Paulo: Brasiliense.

GAMSON, W. 2004. "Bystanders, public opinion, and the media". In: SNOW, D.; SOULE, S.; KRIESI, H. (orgs.). The blackwell companion to social movements. MA, Oxford, Australia: Blackwell Publishers.

GEERTZ, C. 1978[1973]. The interpretation of culture. Rio de Janeiro: Zahar.

GIUGNI, M. 1998. "Introduction: social movements and change: incorporation, transformation, and democratization”. In: ____ McADAM, D.; TILLY, C. (orgs.). From contention to democracy. Londres/Nova Iorque: Rowman/Littlefield Publishers.

; McADAM, D.; TILLY, C. (orgs.). 1998. From contention to democracy. Londres/Nova Iorque: Rowman/Littlefield Publishers. 
JOHNSTON, H.; KLANDERMAS, B. (orgs.) 1995. Social movements and culture. Minneapolis: University of Minneapolis Press.

KANE, A. 1991. "Cultural analysis in historical sociology: the analytic and the concrete forms of the autonomy of culture". Sociological Theory, $\mathrm{n}^{\circ}$ 9(1), pp. 53-69.

KRIESI, H. et al. 1998. New social movements in Western Europe: a comparative analysis. Minneapolis: University of Minnesota Press.

KUGELMAS, E.; SALLUM Jr., B. 1993. "O Leviatã acorrentado: a crise brasileira dos anos 80". In: SOLA, L. Estado, mercado e democracia: política e economia comparadas. São Paulo: Paz e Terra.

LAMOUNIER, B. 1985. "Impasses e alternativas: o Brasil diante da crise". In: PLASTINO, C.; BOUZAR, R. (orgs.). A América Latina e a crise internacional. Rio de Janeiro: Edições Graal.

1988. “O 'Brasil autoritário' revisitado: o impacto das eleições para a abertura. In: STEPAN, A. Democratizando o Brasil. Rio de Janeiro: Paz e Terra.

1996. "Conceptual origins, current problems and future directions”. In: McADAM D.; McCARTHY, J.; ZALD, M. (orgs.). Comparative perspectives on social movements - Political opportunities, mobilizing structures and cultural framings. Cambridge: Cambridge University Press.

McADAM, D.; McCARTHY, J.; ZALD, M. (orgs.) 1996. Comparative perspectives on social movements - Political opportunities, mobilizing structures and cultural framings. Cambridge: Cambridge University Press.

.; McCARTHY, J.; ZALD, M. 1996. "Introduction: Opportunities, mobilizing structures and framing processes - Towards a synthetic, comparative perspective on social movements". In: ; (orgs.). Comparative perspectives on social movements - Political opportunities, mobilizing structures and cultural framings. Cambridge: Cambridge University Press.

; TARROW, S.; TILLY, C. 2001. Dynamics of contention. Cambridge: Cambridge University Press.

McCARTHY, J. 1996. "Adopting, adapting and inventing”. In: McADAM, D.; McCARTHY, J.; ZALD, M. (orgs.). Comparative perspectives on social movements - Political opportunities, mobilizing structures and cultural framings. Cambridge: Cambridge University Press.

MELUCCI, A. 1985. "The symbolic challenge of contemporary movements”. Social Research, n 52, pp. 789-815. . 1995. "The process of collective identity". In: JOHNSTON, H.; KLANDERMAS, B. (orgs.). Social movements and culture. Minneapolis: University of Minneapolis Press. 
MEYER, D.; WHITTIER, N.; ROBNETT, B. (orgs.). 2002. Social movements - Identity, culture and the State. Oxford: Oxford University Press.

NORONHA, E. 1991. "Explosão das greves nos anos 80". In: BOITO Jr., A. Sindicalismo brasileiro nos anos 80. Rio de Janeiro: Paz e Terra.

OFFE, K. 1985. "New social movements: challenging the boundaries of institutional politics". Social Research, $\mathrm{n}^{\circ}$ 52, pp. 817-868.

PLASTINO, C.; BOUZAR, R. (orgs.). 1985. A América Latina e a crise internacional. Rio de Janeiro: Edições Graal.

RAMBO, E.; CHAN, E. 1990. "Text, structure and action in cultural sociology”. Theory and Society, no 19(5), pp. 635-648.

RODRIGUES, L. 1991. "As tendências políticas na formação das centrais sindicais”. In: BOITO Jr., A. Sindicalismo brasileiro nos anos 80. Rio de Janeiro: Paz e Terra.

RUCHT, D. 1996. "The impact of national contexts on social movement structures: a cross-movement and cross-national comparison". In: McADAM, D.; McCARTHY, J.; ZALD, M. (orgs.). Comparative perspectives on social movements - Political opportunities, mobilizing structures and cultural framings. Cambridge: Cambridge University Press.

SALLUM JR., B. 1996. Labirintos - Dos generais à Nova República. São Paulo: Hucitec.

2004. “Crise, democratização e liberalização no Brasil”. In: . (org.). Brasil e Argentina hoje. Bauru-SP: Edusc.

SANDOVAL, S. 1994. Os trabalhadores param: greves e mudança social no Brasil, 1945-1990. São Paulo: Ática.

. 1998. "Social movements and democratization: the case of Brazil and the Latin countries". In: GIUGNI, M. et al. (orgs.). From contention to democracy. Boston: Rowman e Littlefield Publishers.

SEWELL Jr., W. 1985. "Ideologies and revolutions: reflections on the French case”. The Journal of Modern History, $\mathrm{n}^{\circ} 57$ (1), pp. 57-85.

SHILS, E. 1975. "Center and periphery". In:___ Center and periphery Essays in macro-sociology. Chicago e Londres: University of Chicago Press.

SKOCPOL, T. 1979. States and social revolutions. Cambridge: Cambridge University Press.

SNOW, D. 2004. "Framing processes, ideology, and discursive fields". In: SNOW, D.; SOULE, S.; KRIESI, H. (orgs.). The Blackwell companion to social movements. MA, Oxford, Australia: Blackwell Publishers.

; BENFORD, R. 1988. "Ideology, frame resonance, and participant mobilization”. In: KLANDERMAS, B.; KRIESI, H.; TARROW, S. (orgs.). International social movement research. From structure to action: comparing social movement research across cultures. London: Jai Press. 
; SOULE, S.; KRIESI, H. (orgs.). 2004. The Blackwell companion to social movements. MA, Oxford, Australia: Blackwell Publishers.

;___ ; _ _ 2004. "Mapping the terrain”. In:

; _ (orgs.) The Blackwell companion to social movements.

MA, Oxford, Australia: Blackwell Publishers.

; BENFORD, R. 2000. "Framing processes and social move-

ments: an overview and assessment”. Annual Review of Sociology, $\mathrm{n}^{\circ} 26$, pp. 611-639.

et al. 1986. "Frame alignment processes, micromobilization and movement participation”. American Sociological Review, vol. 51, pp. 464481.

SOLA, L. 1993. Estado, mercado e democracia: política e economia comparadas. São Paulo: Paz e Terra.

STAGGENBORG, S. 2002. “The 'meso' in social movement research”. In: MEYER, D.; WHITTIER, N.; ROBNETT, B. (orgs.) Social movements Identity, culture and the State. Oxford: Oxford University Press.

STEINBERG, M. 2002. "Toward a more dialogical approach to social movement culture". In: MEYER, D.; WHITTIER, N.; ROBNETT, B. (orgs.) Social movements - Identity, culture and the State. Oxford: Oxford University Press.

196 STEPAN, A. 1988. Democratizando o Brasil. Rio de Janeiro: Paz e Terra.

SWIDLER, A. 1995. "Cultural power and social movements". In: JOHNSTON, H.; KLANDERMAS, B. (orgs.) Social movements and culture. Minneapolis: University of Minneapolis Press.

TARROW, S. 1998. Power in movement: social movements, collective action and politics. Cambridge: Cambridge University Press.

; TILLY, C. 2007. Contentious politics. Boulder/London: Paradigm Publishers.

TIRYAKIAN, E. 2005. "Durkheim, solidarity and September 11". In: ALEXANDER, J.; SMITH, P. The Cambridge companion to Durkheim. Cambridge: Cambridge University Press.

TOURAINE, A. 1985. "An introduction to the study of social movements". Social Research, $\mathrm{n}^{\circ}$ 52, pp. 749-787.

ZALD, M. 1996. Culture, ideology and strategic framing. In: McADAM, D.; McCARTHY, J.; ZALD, M. (orgs.) Comparative perspectives on social movements - Political opportunities, mobilizing structures and cultural framings. Cambridge: Cambridge University Press. 


\section{"EU QUERO VOTAR PARA PRESIDENTE": UMA ANÁLISE SOBRE A CAMPANHA DAS DIRETAS}

\section{EDISON RICARDO EMILIANO BERTONCELO}

O tema deste artigo é a Campanha das Diretas-Já. Nele, buscamos investigar a emergência desse movimento marcante da história brasileira e seu impacto sobre a transição política para além do regime militar, utilizando um quadro analítico construído com base nas contribuições recentes da literatura sobre ação coletiva e sociologia da cultura.

Palavras-chave: Campanha das Diretas-Já; Crise política; Movimentos sociais; Democratização; Cultura.

\section{"I WANT TO VOTE FOR PRESIDENT": AN ANALYSIS OF THE "DIRETAS-JÁ" CAMPAIGN}

The main theme of this article is the "Campanha das Diretas-Já". We aim to investigate the emergence of this important movement to the Brazilian history and its impact on the political transition beyond the military regime, based on an analytical framework derived from recent contributions by the literature on collective action and cultural sociology.

Keywords: "Diretas-Já" Campaign; Political crisis; Social movements; Democratization; Culture. 